\title{
Application of epoxy putty external skeletal fixator for stabilization of tarsocrural arthrodesis in small dogs and cats
}

\author{
Je-Sung Moon ${ }^{1}$, June-Sub Lee ${ }^{2}$, Hyun-Jung Han ${ }^{1, *}$ \\ ${ }^{I}$ Department of Veterinary Emergency and Critical Care, Konkuk Veterinary Medical Teaching Hospital, Konkuk University, \\ Seoul 05029, Korea \\ ${ }^{2} 7500$ Animal Medical Center, Seoul 06021, Korea
}

\begin{abstract}
Two small-breed dogs and two cats, with an average body weight of $4.88 \mathrm{~kg}$ (range: $4.3-5.5 \mathrm{~kg}$ ), suffered hindlimb lameness due to luxation with or without fractures of the tarsocrural joint. These patients underwent tarsocrural arthrodesis with epoxy putty external skeletal fixator. The animals' skins were incised minimally, and the articular cartilage of the tarsocrural joint was removed, followed by autogenous cancellous bone grafting. Epoxy putty and positive Centerface ${ }^{\circledR}$, pins with diameters $1.2 \mathrm{~mm}$ and $2.0 \mathrm{~mm}$, were used for connecting bar and as a full pin fixation, respectively. All the patients regained the ability to bear weight on the affected limb within 3-7 days and resumed a normal gait within 9-15 weeks. The external skeletal fixator frame was removed within 13-17 weeks without major complications. Tarsocrural arthrodesis using epoxy putty external skeletal fixator resulted in excellent outcomes without severe postoperative complications in this study. Epoxy putty external skeletal fixator can be a valuable surgical option for tarsocrural arthrodesis in patients weighing less than $5.5 \mathrm{~kg}$.
\end{abstract}

Keywords: cats, epoxy putty, external skeletal fixator, small dogs, tarsocrural arthrodesis

*Corresponding author

Hyun-Jung Han

Department of Veterinary Emergency and Critical Care, Konkuk Veterinary Medical Teaching Hospital, Konkuk University, Seoul 05029, Korea

Tel: $+82-2-450-3664$

Fax: +82-2-450-3037

E-mail: ab1234@konkuk.ac.kr

ORCID

Je-Sung Moon

https://orcid.org/0000-0001-9304-2119

June-Sub Lee

https://orcid.org/0000-0001-5612-7172

Hyun-Jung Han

https://orcid.org/0000-0002-1910-1261

Conflict of Interest

The authors declare no conflict of interest.

Received: June 23, 2020

Revised: August 18, 2020

Accepted: September 10, 2020

\section{Introduction}

Tarsocrural arthrodesis is a salvage procedure for the joint, particularly for joints with a severe shearing injury, which inevitably develop osteoarthritis $[1,2]$. Further, tarsocrural arthrodesis leads to a complete osseous union of the joint for permanent stabilisation by removal of articular cartilage, grafting of cancellous bone, and rigid fixation [1]. For rigid fixation of the joint, plated arthrodesis is the preferred method in veterinary medicine. However, serious complications-such as implant failure, infection, iatrogenic bone fracture, and postoperative soft tissue injury-can occur due to the selected plate strength, excessive soft tissue tension, and damage resulting in reduced blood supply [1,3-6]. Especially in small dogs and cats, the risk for complications of plated arthrodesis may be higher because of the small bones and the lack of soft tissue making up the tarsal joint [7]. Therefore, other surgical methods that reduce the risk of complications while maintaining a rigid fixation could be an alternative for successful tarsocrural arthrodesis in small dogs and cats. This case report describes the surgical technique and successful outcomes of epoxy putty-external skeletal fixator (EP-ESF) for tarsocrural arthrodesis in four small dogs and cats.

\section{Materials and Methods}

\section{History and clinical findings}

Medical records of four small animals (two dogs and two cats) treated by tarsocrural arthrodesis with EP-ESF during two years (2017-2019) were reviewed (Table 1). The dogs and cats were aged 3-7 years (mean \pm SD: $4.5 \pm$ 1.73 ), and their body weights were $4.3-5.5 \mathrm{~kg}$ (mean \pm SD: $4.88 \pm 0.61 \mathrm{~kg}$ ). The breeds included a Maltese, a toy poodle, and two domestic shorthaired cats.

All patients were admitted with a primary complaint of acute hindlimb lameness caused by various traumas (hit by a car [case 1], falling accident [cases 2 and 4], and an unknown cause [case 3]). Case 3 was presumed to be 
Table 1. Case summaries of four animals treated with tarsocrural arthrodesis using epoxy putty-external skeletal fixation

\begin{tabular}{|c|c|c|c|c|c|c|c|c|c|c|c|}
\hline \multirow{3}{*}{$\begin{array}{l}\text { Case } \\
\text { No. }\end{array}$} & \multirow{3}{*}{ Signalment } & \multirow{3}{*}{$\begin{array}{l}\text { Preoperative } \\
\text { radiographs }\end{array}$} & \multirow{3}{*}{$\begin{array}{l}\text { Duration } \\
\text { from injury } \\
\text { to surgery }\end{array}$} & \multicolumn{3}{|c|}{$\begin{array}{c}\text { Number/diameter of fixation full } \\
\text { used }\end{array}$} & \multicolumn{4}{|c|}{ Clinical outcome } & \multirow{3}{*}{ Complications } \\
\hline & & & & \multirow[b]{2}{*}{$\begin{array}{l}\text { Tibia } \\
(\mathrm{mm})\end{array}$} & \multirow{2}{*}{$\begin{array}{c}\text { Talus/ } \\
\text { calcaneus } \\
\text { tarsal bones } 1 \\
(\mathrm{~mm})\end{array}$} & \multirow[b]{2}{*}{$\begin{array}{l}\text { Metatarsal } \\
\text { bone (mm) }\end{array}$} & \multirow[b]{2}{*}{ Result } & \multicolumn{3}{|c|}{ Duration from surgery to } & \\
\hline & & & & & & & & $\begin{array}{l}\text { Weight- } \\
\text { bearing }\end{array}$ & Normal gait & $\begin{array}{l}\text { Frame } \\
\text { removal }\end{array}$ & \\
\hline 1 & $\begin{array}{c}\text { Canine } \\
\text { Maltese } \\
4.3 \mathrm{~kg} \\
7 \mathrm{yr}\end{array}$ & $\begin{array}{l}\text { TC luxation, } \\
\text { Multiple } \\
\text { fractures of } \\
\text { right talus }\end{array}$ & $5 \mathrm{~d}$ & $2 \times 1.6$ & $2 \times 1.4$ & $1 \times 1.2$ & Good* $^{*}$ & $3 \mathrm{~d}$ & $9 \mathrm{wk}$ & $17 \mathrm{wk}$ & $\begin{array}{l}\text { Pin tract } \\
\text { discharge }\end{array}$ \\
\hline 2 & $\begin{array}{l}\text { Feline } \\
\text { DSH } \\
5.3 \mathrm{~kg} \\
4 \mathrm{yr}\end{array}$ & $\begin{array}{l}\text { TC luxation, } \\
\text { Distal fibular } \\
\text { fracture }\end{array}$ & $2 \mathrm{~d}$ & $\begin{array}{l}1 \times 1.6 \\
1 \times 1.8\end{array}$ & $\begin{array}{l}2 \times 1.6 \\
1 \times 1.4\end{array}$ & & Good $^{*}$ & $3 \mathrm{~d}$ & $15 \mathrm{wk}$ & $15 \mathrm{wk}$ & \\
\hline 3 & $\begin{array}{l}\text { Feline } \\
\text { DSH } \\
4.4 \mathrm{~kg} \\
3 \mathrm{yr}\end{array}$ & TC luxation & $1 \mathrm{yr}$ & $2 \times 1.8$ & $\begin{array}{l}1 \times 1.4 \\
1 \times 1.6\end{array}$ & $2 \times 1.4$ & Good $^{*}$ & $3 \mathrm{~d}$ & $11 \mathrm{wk}$ & $13 \mathrm{wk}$ & $\begin{array}{l}\text { Pin tract } \\
\text { discharge }\end{array}$ \\
\hline 4 & $\begin{array}{c}\text { Canine } \\
\text { Toy poodle } \\
5.5 \mathrm{~kg} \\
4 \mathrm{yr}\end{array}$ & $\begin{array}{l}\text { TC luxation, } \\
\text { Multiple } \\
\text { fractures of } \\
\text { distal fibula \& } \\
\text { talus }\end{array}$ & $3 \mathrm{~d}$ & $\begin{array}{l}2 \times 2.0 \\
1 \times 1.8\end{array}$ & $\begin{array}{l}1 \times 1.8 \\
1 \times 1.6\end{array}$ & $\begin{array}{l}1 \times 1.4 \\
1 \times 1.4\end{array}$ & Good* $^{*}$ & $7 \mathrm{~d}$ & $11 \mathrm{wk}$ & $17 \mathrm{wk}$ & $\begin{array}{l}\text { Damage to the } \\
\text { epoxy putty } \\
\text { connecting bar }\end{array}$ \\
\hline
\end{tabular}

DSH, domestic shorthair; TC, tarsocrural.

*Good, normal gait with full weight-bearing.
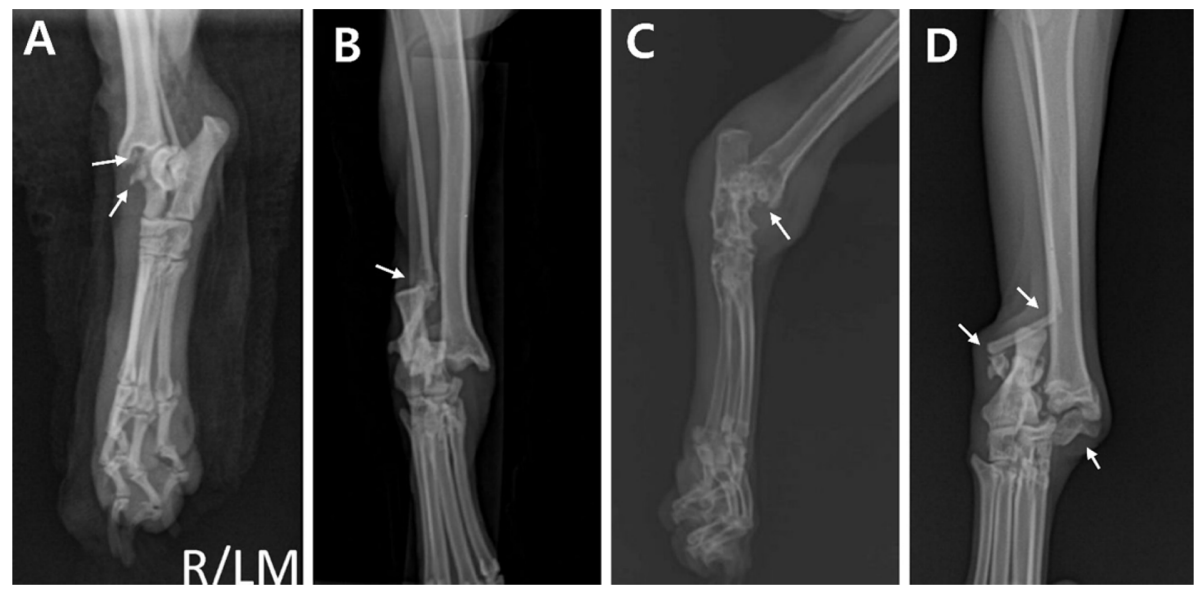

Fig. 1. Preoperative radiographic views of the right tarsal joints. (A) Tarsocrural luxation and multiple bony fragments between tibia and talus indicating fractures of talus trochlear in case 1 (white arrows). (B) Tarsal joint luxation and bone resorption sign in case 2. (C) tarsal joint luxation in case 3. (D) Tarsocrural luxation, fracture of distal fibula and talus in case 4.

caused by traumatic injury during a short walk outside because the animal showed sudden lameness after returning home; this cat was untreated for one year and finally received medical care after adoption by another family. Initially, the cat was treated by pantarsal arthrodesis using a plate and screw, but the first surgery failed five days postoperatively because of broken implants. The animal was then transferred to our hospital for additional surgery. On physical examination, the cases showed tarsal hyperextension, plantigrade on standing, and lameness of the affected hindlimb, including toe-touching lameness (case 2) and non-weight bearing lame- ness (cases 1, 3, and 4). Additionally, the patient in case 1 suffered a soft tissue injury in which skin shearing was noticed medial to the affected tarsal joint.

\section{Imaging diagnosis}

Preoperative standard radiographs of the lesions of the tarsal joint and other associated abnormalities, such as fractures and ligamentous injury, were evaluated. All patients were diagnosed with tarsocrural luxation, and additional fractures were identified in cases 1,2, and 4: multiple fractures of the medial trochlear of the right talus in case 1; distal fibular 
fracture in case 2; and multiple fractures of the distal fibula and talus in case 4 (Fig. 1). In case 3, the laterally applied plate on the tarsal joint was bent and broken with a loosened screw; irregular periosteal reaction and osteolytic changes were observed on the tarsal joint.

\section{Surgery}

Tarsocrural arthrodesis using EP-ESF was performed in all cases. The procedure was performed in the dorsal recumbency with the affected limb elevated. The affected joint was exposed via a dorsal approach to the tarsus, for removal of the articular cartilage and autogenous bone grafting. The skin was minimally incised as needed for the tarsal joint exposure, which extended from the proximal calcaneus to the proximal metatarsal bones, except for case 3 . In case 3 , the skin incision was extended from the distal one-third of the tibia to midway down the metatarsal bone for removal of the previously loaded implants. A culture of the removed implants was performed in case 3, which showed no bacterial growth.

After joint exposure, the articular cartilage of the tarsocrural joint was removed with a rongeur, curette, and a pneumatic burr, followed by joint lavage with sterile saline. An autogenous cancellous bone graft, harvested from the ipsilateral proximal humerus, was packed into the joint space. After the bone graft, the surgical wound was closed as per routine.

For the tarsocrural stabilisation, EP-ESF was applied in all the cases based on the general principles of ESF [7]. A maximal type II frame, consisting of full pins, was constructed in all cases. Assorted sizes (from 1.2-2.0 mm diameter) of centrally threaded positive profile pins were selected, which did not exceed $25-30 \%$ of the maximum diameter of the bone (Table 1). The fixation pins were placed (by a closed approach under $\mathrm{C}$-arm guidance) with a low-speed drill in the following locations: two pins in the tibial diaphysis and epiphysis, the centre of the talus trochlea or calcaneus, the tarsal bones, and the proximal part of the metatarsal bones (Fig. 2). The bilateral ends of the fixation pins were bent at right angles in cases 1,2 , and 4 , and these bent parts of the pins were overlapped into lines parallel to the axis of the affected limb to act as a scaffold for the EP connecting bar. In case 1 and 4 , the $2.0 \mathrm{~mm}$ Steinmann pins were added as an additional scaffold for the EP connecting bar to reinforce the connection of the fixation pins and to increase the strength of the EP connecting bar.

After all the pins were placed, the affected tarsal joint was equally angled to the premeasured normal standing angle of the opposite tarsal joint, and 1.2-mm K-wire was placed across the arthrodesis site from the caudal part of the talus through the tibial bone marrow cavity for temporary maintenance of the fusion angle. Then, the EP was applied for the construction of a connecting bar with a roughly $2 \mathrm{~cm}$ diameter (Fig. 3). Care was taken to cover the fixation pins and the Steinmann pins that were acting as a scaffold. The EP connecting bar was placed 1-2 cm away from the skin surface to prevent compressive skin injury due to postoperative soft tis-

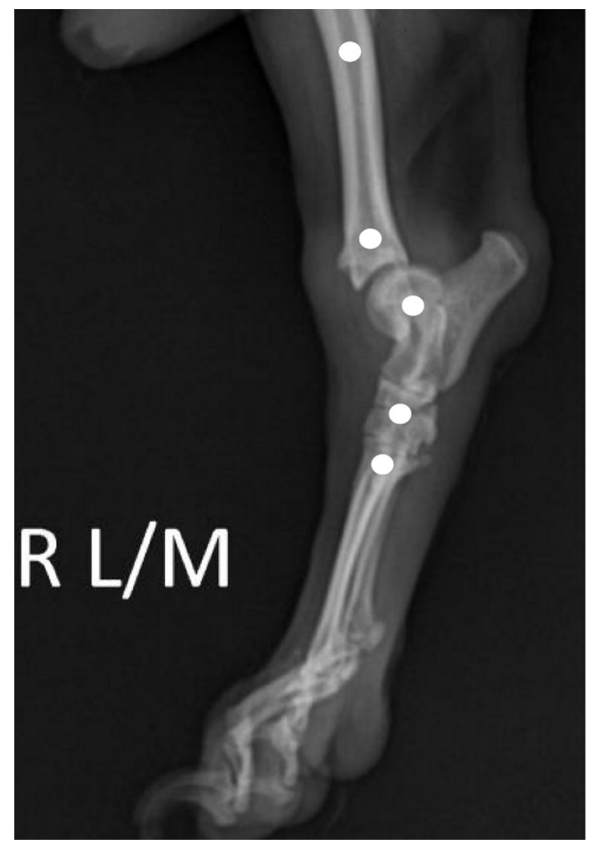

Fig. 2. The location of the fixation full pins are indicated on the lateral view of the preoperative radiograph of the tarsal joint. The pins are placed in the tibial diaphysis and epiphysis, center of talus trochlear, and the central tarsal bone and the tarsal bone $\mathrm{IV}$, and the proximal metatarsal bone (white circles).

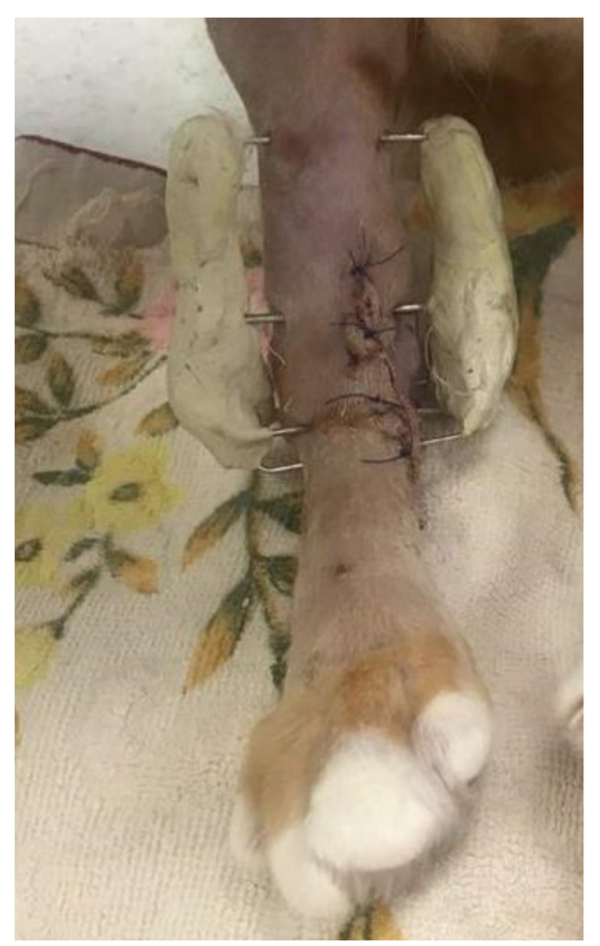

Fig. 3. Photograph of the tarsocrural arthrodesis using epoxy putty external skeletal fixator of a case 2 . Full fixation pins are placed in tibia, talus/calcaneous, tarsal bones and epoxy putty connecting bar is constructed with a roughly $2 \mathrm{~cm}$ diameter and 1-2 $\mathrm{cm}$ distance between the bar and the skin surface. 
sue swelling. After the EP was wholly hardened, the temporary $\mathrm{K}$-wire was removed.

\section{Results}

Postoperative radiographs were immediately obtained to check for correct pin placement and alignment of the tarsal joint. Postoperative care included daily sterilisation of the surgical wound with saline and chlorhexidine solution, cold massage for $72 \mathrm{~h}$, and analgesics, including fentanyl and lidocaine CRI, for $24 \mathrm{~h}$ (fentanyl: $4 \mu \mathrm{g} / \mathrm{kg}$ loading and $4 \mu \mathrm{g} /$ $\mathrm{kg} / \mathrm{h} \mathrm{CRI}$; lidocaine: $0.5 \mathrm{mg} / \mathrm{kg}$ loading and $1.2 \mathrm{mg} / \mathrm{kg} / \mathrm{h} \mathrm{CRI})$ followed by a nonsteroidal anti-inflammatory drug (carprofen: $4.4 \mathrm{mg} / \mathrm{kg}$ PO for $24 \mathrm{~h}$ ) for 7-14 days postoperatively. In case 1 , the traumatic skin shearing was treated by flushing with sterilised normal saline and honey dressing and left to heal by second intention.

The patients were hospitalised for 3-7 days. After discharge, the owners were instructed to restrict exercise for four to six weeks, including short leash walking for the dogs and room or cage confinement for the cats. After radiographic confirmation of complete osseous union and restored normal gait, the ESF frame was gradually removed in three stages over two-week intervals. In the first and second stages, the pin was cut at the level of the pin-to-putty interface without sedation. The first cutting was performed at the two fixation pins closest to the tarsocrural joint, and after two weeks, the second cutting was performed at the next fixation pins located just proximal or distal of the previously cut pins.
Finally, in the third stage, the remaining most proximal and distal pins were cut, and the entire frame was removed using a Jacobs hand chuck under deep sedation or general anaesthesia. After frame removal, a soft bandage was applied, as a precautionary measure for one week, to support the weakened bone due to the resulting pinhole.

Postoperative outcomes were evaluated during periodic inhospital examinations by visual inspection (including gait and surgical wound status), serial radiographic examination, and by telephone follow-ups with owners.

Postoperative gait was assessed, in the hospital, on postoperative days $0,3,7,14$, and 21 . Long-term evaluation continued every two weeks for periods ranging from 12 to 43 months (median of 32 months). Gait in all patients improved consistently because of the surgery, despite being temporarily non-weight bearing immediately after surgery. On the third day postoperatively, three patients (cases 1, 2, and 4) were weight-bearing during standing. However, case 3 showed consistent toe-touching lameness. On the seventh day, the other patients were weight-bearing walking most of the time, and case 3 also improved to weight-bearing standing and sometimes weight-bearing walking. By the fourteenth day, all patients showed almost regular weight-bearing walking. However, weight shifting and mild lameness were noted when the dogs were trotting or running. The gait returned to normal without residual lameness in all patients within 15 weeks (range: 9-15 weeks; median 11 weeks; Table 1).

Immediate postoperative radiographs revealed an excellent
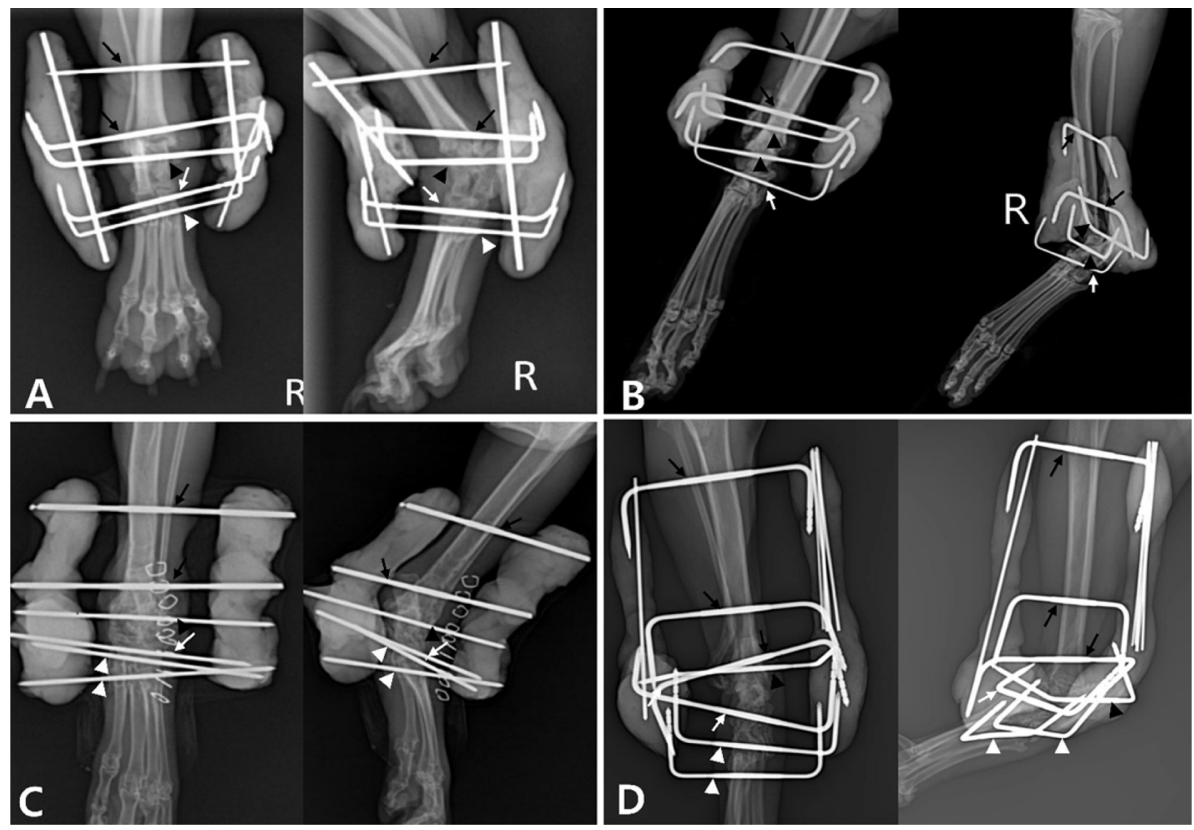

Fig. 4. Initial postoperative radiographs represents tarsocrural arthrodesis using epoxy putty external skeletal fixator in case 1 (A), case 2(B), case 3 (C), case 4 (D). 1.2 2.0 mm diameter of full pins were placed in tibial diaphysis and distal epiphysis (black arrows), talus and/or calcaneous (black arrowheads), tarsal bones (white arrows), and metatarsal bones (white arrowheads) respectively. Epoxy putty was applied to construct a connecting bar with or without the Steinmann pins. 


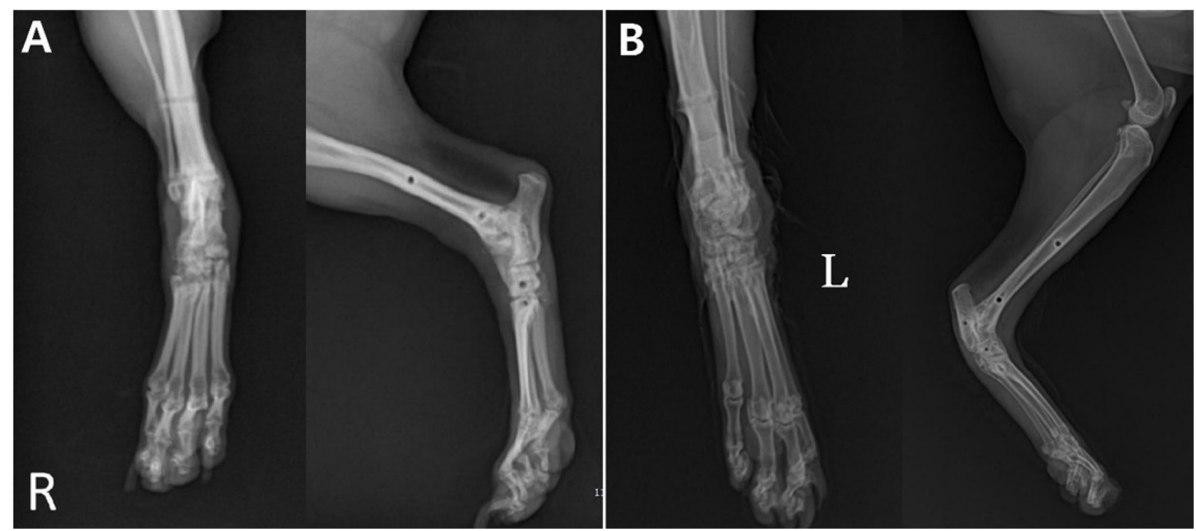

Fig. 5. Postoperative radiographs showing completely healed arthrodesis of tarsocrural joint in a case 1 (A) and case 3 (B). This radiographs is taken immediately after removal of epoxy putty external skeletal fixator. Pin holes are observed where the fixation pin was placed.
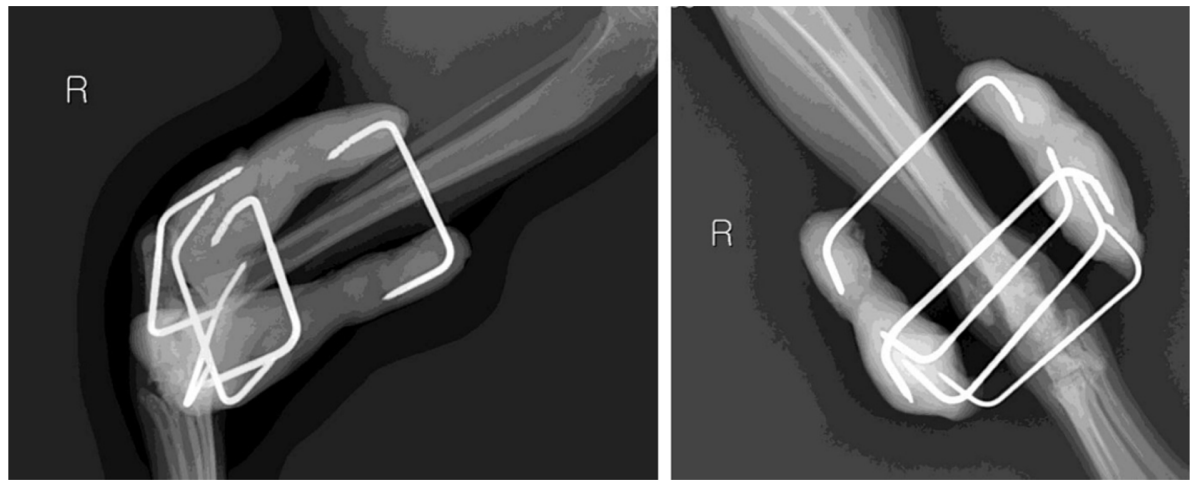

Supplementary Fig. 1. Final radiographic images of case 2. This patient had returned to the referring hospital postoperatively, and the referring veterinarian did not take a radiograph after whole removal of the frame due to owner's financial problem.

reduction of the tarsocrural joint with proper implant placement in all cases (Fig. 4). During the follow-up period, no implant failures, such as implant loosening or infection, were noted and progressive healing of the tarsocrural arthrodesis was observed in all cases. After radiographic confirmation of the complete osseous union, the frame was removed between 13 and 17 weeks postoperatively (median 15 weeks; Table 1, Fig. 5, Supplementary Figs. 1 and 2). In case 1, the dog presented temporary pain and partial weight-bearing lameness after the frame removal but returned to normal gait immediately after a short-term (3 days) administration of an oral nonsteroidal anti-inflammatory drug.

Perioperative complications were not reported in any of the cases. Postoperative complications were identified in two cases, including pin tract infection leading to minimal tissue inflammation and serous discharge around the pin-skin contact point. These were superficial pin-tract infections that did not progress to a deep infection of soft tissues or bones and were easily managed by local disinfection. In case 3, traumatic damage to the EP connecting bar was identified nine weeks after surgery. Therefore, EP was added to repair the connecting bar.
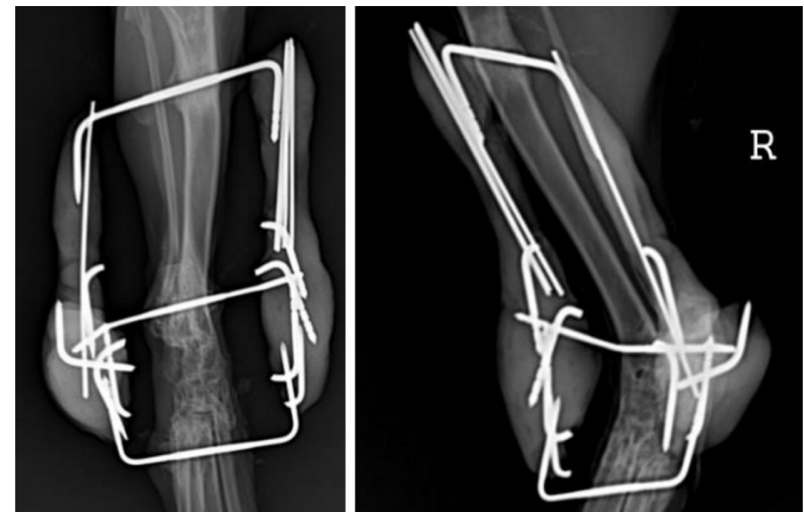

Supplementary Fig. 2. Final radiographic images of case 4. This patient had returned to the referring hospital postoperatively, and the referring veterinarian did not take a radiograph after whole removal of the frame due to owner's financial problem.

During long-term telephonic follow-ups, all the owners reported that their pets had fully recovered to a normal gait without any complications. There was no lameness recurrence in the affected limb in any of the cases. 


\section{Discussion}

In small animals with tarsal instability, ESF has been used for temporary immobilisation of unstable tarsal joints or rigid fixation in arthrodesis [8-15]. While ESF is a well-documented, preferred joint immobilisation technique for the temporary stabilisation of tarsocrural instability $[12,14,15]$, its application for tarsocrural arthrodesis has rarely been reported and has only had limited use in joints with severe soft tissue injury requiring constant management of an open wound $[10,13,14]$. Plated arthrodesis has been recognised as the most effective method for successful tarsocrural arthrodesis $[5,6,9,16]$, but most earlier reports were limited to medium-sized or bigger dogs that have relatively more options for plate selection compared to small-sized dogs and cats $[3,16]$. Thus far, we know of only one study reporting the outcomes and complications of tarsal arthrodesis in small-sized dogs and cats weighing less than $14.5 \mathrm{~kg} .{ }^{5}$ In the study, plate or K-wire was used for 12 and 3 patients, respectively, and postoperative complications associated with the implant, such as skin irritation and implant loosening, were reported in 8 of the 15 patients [5].

In this study, the patients were all small-sized, weighing less than $5.5 \mathrm{~kg}$. We considered that several limitations of plated arthrodesis could be more severe for these small-sized patients due to a thin metatarsal bone and a lack of soft tissue around the tarsal joint. The thin metatarsal bone was considered as the most significant limitation for plated arthrodesis in these small-sized patients. Since the plate size and strength is usually determined by the screw size inserted in the metatarsal bone [17], and the screw should not exceed $20-40 \%$ of the diameter of the metatarsal bone due to the risk of iatrogenic metatarsal fracture $[6,18,19]$, the thinner metatarsal bone could allow for a smaller sized screw and a correspondingly smaller plate. Hybrid plates with different screw sizes and spacing of screw holes have been developed to overcome this limitation. However, they still have limited use in small-sized patients, as they are only available in specific lengths and sizes [4]. In our patients, the diameter of the metatarsal bone was less than $5 \mathrm{~mm}$, and accordingly, a 1.5/ $2.0 \mathrm{~mm}$ plate was the only available option. We were concerned that this size of plate might not provide enough strength for tarsocrural stabilisation due to the high motion of the tarsocrural joint and the vigorous activity of these patients [3]. Particularly, in case 3, another surgical option had to be considered because implant failure had previously occurred after tarsocrural arthrodesis using a 1.5/2.0 mm plate.

By using ESF, the overall strength of the implant is increased for tarsocrural arthrodesis in these small-sized dogs and cats for the following reasons. First, we need not be concerned about the thin metatarsal bone because of the features of the ESF frame. Unlike the plated arthrodesis, the connecting bar of the ESF frame can hold the different sized pins matched to each bone simultaneously, so that the frame size and strength was not affected by the diameter of the metatar- sal bone. Additionally, we used type II ESF so that the connecting bars were placed bilaterally, and this ESF frame is considered to be able to provide superior stiffness compared with the plate placed on only one side of the joint dorsally or laterally. Because the plate could not be placed on the plantar surfaces, which is a tension side of the tarsal joint, it could be easily deformed when eccentric loading is applied to the tarsal joint [20]. Thus, external coaptation is generally required for plated arthrodesis in order to avoid fatigue failure before bony healing occurs [20,21].

Complications of external coaptation, such as pressure sores, ischemic injury, and wound dehiscence, are severe problems of plated arthrodesis, and these commonly occur at $12-40 \%$ of the time $[4,6,20,22,23]$ and pose disastrous consequences if left untreated for even a few days [20,21]. In this study, no postoperative external coaptations were applied to any of the patients due to sufficient strength of ESF for tarsocrural stabilisation without the need for external coaptation. Thus, complications related to postoperative external coaptation did not occur. Moreover, since there was no external coaptation, easy access for open wound management in case 1 was possible. Additionally, other complications related to internal implants, including excessive soft tissue tension, compromised blood supply, constant irritation of the soft tissue, and implant-related infection, were not identified in these patients, even though the lack of loose soft tissue could be more severe in these small-sized patients $[1,3,18,24]$. We considered it was because the externally placed connecting bar prevented these complications by avoiding excessive soft tissue dissection and internally placed implant. In this study, only minor complications associated with the implant occurred, such as pin tract infection in two cases. Pin tract infection represents most of the complications in ESF and is managed easily with local disinfection and antibiotics [9]. In this study, the infections were easily manageable and selflimiting.

In this study, tarsocrural joint exposure was inevitable for the complete osseous union of the joint, leading us to waive one of the most significant advantages of ESF, which is avoiding additional disturbance to compromised soft tissue and preserving the blood supply by a closed approach [1]. However, the extent of the skin incision and soft tissue dissection could be significantly reduced compared with plated arthrodesis because the skin was incised only for the tarsocrural joint exposure without the dissection of the subcutaneous space for implant loading.

As a connecting bar, this study used EP, as the size of these patients limited the traditional clamp-and-rod system. The clamp-and-rod system can be challenging to use on tiny bones or areas due to the difficulty of placing the clamps very close together [8]. In these patients, fixation pins were placed very close to each other, and there was no space for the placement of clamps between the fixation pins. The distance between each fixation pin was $2-8 \mathrm{~mm}$. Thus, a 9-mm clamp could not be placed on the pins. Furthermore, due to 
the nature of the angled tarsal joint, it was challenging to place the fixation pins on a single plane, which makes the frame of the linear connecting bar more complicated, which limited the application of a traditional linear connecting rod, such as stainless steel or titanium. Previous studies reported that these limitations of the traditional clamp-and-rod system could be overcome using acrylic or EP connecting bars $[8,20,25]$. In this study, EP successfully held the fixation pin regardless of the spaces between the pins and linear conformation of the pins. Moreover, other reported benefits of EP as a connecting bar, such as facilitating the use of various sized pins, cost-effectiveness, and mouldable features that allow easy handling, were also useful in these small-sized patients $[8,25]$. In this study, EP was damaged postoperatively due to patient-inflicted trauma in case 3 . This complication of EP was also reported in the previous study using EP-ESF for fractures of metacarpal or metatarsal bones in cats and dogs [8]. In both this and the previous study, the patient-inflicted trauma of the EP connecting bar was minor and did not affect the overall ESF frame strength, and it was easily managed by adding EP to the injured area postoperatively. Apart from this complication, there were no other specific complications associated with $\mathrm{EP}$, including the weight of the EP or the thermal damage due to heat generated during its hardening.

In this study, intertarsal and tarsometatarsal joints were not exposed for arthrodesis, and no procedure for a complete osseous union was performed in these joints, as there was no significant instability and no soft tissue injury in the intertarsal and tarsometatarsal area. A previous study reported that joint ankyloses using ESF without joint exposure was very effective in stabilising the tarsometatarsal luxation by joint capsule shortening, proliferation, increased cross-linking of collagen fibrils in periarticular connective tissue, and articular cartilage atrophy [11]. Based on this report, we expected that these low-motion joints, including the intertarsal and tarsometatarsal joints, could stabilise by joint ankylosis, resulting in increased strength of the periarticular soft tissue structure, not by osseous union. As a result, excellent outcomes were achieved, and there were no clinical complications associated with these joints, despite the treatment involving only tarsocrural arthrodesis without a complete osseous union of intertarsal and metatarsal joints.

In this study, four small-sized dogs and cats with tarsocrural luxation were successfully treated with a tarsocrural arthrodesis using EP-ESF. These results highlight that a tarsocrural arthrodesis using EP-ESF is a feasible salvage procedure in small-sized patients weighing less than $5.5 \mathrm{~kg}$, with excellent outcomes and less implant-related complications.

\section{References}

1. Piermattei DL, Flo GL. Handbook of Small Animal Orthopedics and Fracture Repair. 3rd ed. pp. 201-217, 607655, Saunders, Philadelphia, 1997.

2. Johnson KA. Arthrodesis. In: Olmstead ML (ed.). Small
Animal Orthopedics. pp. 503-529, Mosby, Saint Louis, 1995.

3. Roch SP, Clements DN, Mitchell RA, Downes C, Gemmill TJ, Macias C, McKee WM. Complications following tarsal arthrodesis using bone plate fixation in dogs. J Small Anim Pract 2008;49:117-126.

4. Fettig AA, McCarthy RJ, Kowaleski MP. Intertarsal and tarsometatarsal arthrodesis using $2.0 / 2.7-\mathrm{mm}$ or $2.7 / 3.5-\mathrm{mm}$ hybrid dynamic compression plates. J Am Anim Hosp Assoc 2002;38:364-369.

5. Théoret MC, Moens NM. The use of veterinary cuttable plates for carpal and tarsal arthrodesis in small dogs and cats. Can Vet J 2007;48:165-168.

6. Dyce J, Whitelock RG, Robinson KV, Forsythe F, Houlton JE. Arthrodesis of the tarsometatarsal joint using a laterally applied plate in 10 dogs. J Small Anim Pract 1998;39:19-22.

7. Kirsch JA, Déjardin LM, DeCamp CE, Meyer EG, Haut RC. In vitro mechanical evaluation on the use of an intramedullary pin-plate combination for pantarsal arthrodesis in dogs. Am J Vet Res 2005;66:125-131.

8. De La Puerta B, Emmerson T, Moores AP, Pead MJ. Epoxy putty external skeletal fixation for fractures of the four main metacarpal and metatarsal bones in cats and dogs. Vet Comp Orthop Traumatol 2008;21:451-456.

9. Beever LJ, Giles K, Meeson RL. Postoperative complications associated with external skeletal fixators in dogs. Vet Comp Orthop Traumatol 2018;31:137-143.

10. Diamond DW, Besso J, Boudrieau RJ. Evaluation of joint stabilization for treatment of shearing injuries of the tarsus in 20 dogs. J Am Anim Hosp Assoc 1999;35:147-153.

11. McLennan MJ. Ankylosis of tarsometatarsal luxations using external fixation. J Small Anim Pract 2007;48:508-513.

12. Beever LJ, Kulendra ER, Meeson RL. Short and long-term outcome following surgical stabilization of tarsocrural instability in dogs. Vet Comp Orthop Traumatol 2016;29:142-148.

13. Rahal SC, Volpi RS, Hette K, Teixeira Neto FJ, Vulcano LC. Arthrodesis tarsocrural or tarsometatarsal in 2 dogs using circular external skeletal fixator. Can Vet J 2006;47:894-898.

14. Benson JA, Boudrieau RJ. Severe carpal and tarsal shearing injuries treated with an immediate arthrodesis in seven dogs. J Am Anim Hosp Assoc 2002;38:370-380.

15. Kulendra E, Grierson J, Okushima S, Cariou M, House A. Evaluation of the transarticular external skeletal fixator for the treatment of tarsocrural instability in 32 cats. Vet Comp Orthop Traumatol 2011;24:320-325.

16. McKee WM, May C, Macias C, Lapish JP. Pantarsal arthrodesis with a customised medial or lateral bone plate in 13 dogs. Vet Rec 2004;154:165-170.

17. Vannini R, Bonath KH. Arthrodesis of the Tarsus. In: Johnson AL, Houlton JE, Vannini R (eds.). AO Principles of Fracture Management in the Dog and Cat. pp. 466-477, AO Publishing, Davos-Platz, 2006.

18. Li A, Gibson N, Carmichael S, Bennett D. Thirteen pancarpal arthrodeses using 2.7/3.5 mm hybrid dynamic compression plates. Vet Comp Orthop Traumatol 1999;12: 102-107.

19. Anderson M, Aron D, Palmer R. Improving pin selection and insertion technique for external skeletal fixation. Comp Cont Ed Pr Vet 1997;19:485-494.

20. Shanil J, Yeshurun Y, Shahar R. Arthrodesis of the tarsometatarsal joint, using type II ESF with acrylic connecting 
194 Je-Sung Moon, June-Sub Lee, Hyun-Jung Han

bars in four dogs. Vet Comp Orthop Traumatol 2006;19:6163.

21. Anderson DM, White RA. Ischemic bandage injuries: a case series and review of the literature. Vet Surg 2000;29:488-498.

22. Allen MJ, Dyce J, Houlton JE. Calcaneoquartal arthrodesis in the dog. J Small Anim Pract 1993;34:205-210.

23. Muir P, Norris JL. Tarsometatarsal subluxation in dogs: partial arthrodesis by plate fixation. J Am Anim Hosp Assoc
1999;35:155-162.

24. Emmerson TD, Muir P. Bone plate removal in dogs and cats. Vet Comp Orthop Traumatol 1999;12:74-77.

25. Ross JT, Matthiesen DT. The use of multiple pin and methylmethacrylate external skeletal fixation for the treatment of orthopaedic injuries in the dog and cat. Vet Comp Orthop Traumatol 1993;06:115-121. 